\title{
Measuring Personal and Social Responsibility: An Existential Positive Psychology Approach
}

\author{
Gökmen Arslan ${ }^{1,2}$ id and Paul T. P. Wong ${ }^{3}$ i0
}

\begin{abstract}
Responsibility is regarded as essential for wellbeing, and measuring this construct is warranted to develop strategies that promote people's mental health and wellbeing. The purpose of the current study is to investigate the initial development and validation of the Responsibility Questionnaire (RQ) to measure the sense of responsibility of individuals. Participants included two independent samples, comprising of 284 adults, ranging in age between 18 and 84 years. Sample 1 was used to conducted the exploratory factor analysis and comprised of 152 adults (65\% female), ranging in age from 18 to 82 years $(M=43.18, S D=14.68)$. Sample 2 was used to conduct the confirmatory factor analysis. The sample consisted of 132 adults (56\% female), ranging in age from 18 to 84 years $(M=$ $29.08, S D=12.45)$. Findings from exploratory factor analysis revealed the RQ provided a two-factor solution comprising of 8 items that accounted for $46 \%$ of the variance, with equal items targeting characteristics of both personal and social responsibility. Confirmatory factor analysis confirmed the two-factor latent structure, providing good data-model fit statistics. Further results also showed that the internal reliability of the scale and its subscales were strong. Finally, the latent path model revealed that the first-and high-order measurement model had positive and significant predictive effects on life satisfaction and negative predictive effects on psychological distress, accounting for the approximately large variance in the variables. Overall, the results suggest that the RQ could be used to assess personal and social responsibility among adults.
\end{abstract}

Keywords: Responsibility, reliability, validity, rating scale, positive psychology, second-wave positive psychology

Positive psychology emphasizes the importance of virtues and an individual's signature strengths, such as hope and gratitude (Lopez \& Snyder, 2009; Peterson \& Seligman, 2004). In contrast, existential positive psychology (Wong, 2011, 2019a, 2021; Wong et al., in press) emphasis universal core values essential for survival and thriving, especially during difficult times, such as courage, compassion (Chen \& Wu, 2021; Wong, 2020), and responsibility (Wong, 2008; 2016; 2019b).

In the era of COVID-19, the imperative of responsibility is thrust into the forefront of social consciousness. The public health policy of social distancing, wearing masks, and mass vaccination will not work for a determined minority who consider such government imposed mandate as an infringement against their personal liberty (Austen, 2021); such opposition may undermine scientists' effort to end the spread of coronavirus (Ball, 2020). This is a serious public health issue, yet our proposal on the importance of responsibility during the pandemic (Wong et al., 2020) was rejected by a special issue on public psychology.

The positive psychology research on meaning also downplay the role of responsibility. For example, George \& Park, (2016) and Martela \& Steger (2016) declared that a consensus had been reached on a tripartite definition of meaning in life, which excluded that responsibility as a factor, despite the vast literature on responsibility as important for meaningful living (e.g., Arslan \& Y1ldırım, 2021; Frankl, 1946, 1985; Peck, 1978/2012; Peterson,

\footnotetext{
${ }^{1}$ Department of Psychological Counseling, Mehmet Akif Ersoy University, Turkey

${ }^{2}$ Centre for Wellbeing Science, University of Melbourne, Australia

${ }^{3}$ Department of Psychology, Trent University, Canada
}

Corresponding Author: Gökmen Arslan, Department of Psychological Counseling and Guidance, Mehmet Akif Ersoy University, Burdur, Turkey.

Email: garslan@mehmetakif.edu.tr|gokmen.arslan@unimelb.edu.au 
2018; Wong, 2008, 2019a). Even common sense would dictate that it is impossible for anyone to live a meaningful life in a free society with almost an infinite number of pathways, unless that person assumes the responsibility to pursue one's ideal rather than letting others decide on one's future. In fact, Wong (2019b) considers responsibility the key to living a meaningful and productive life, as seen in Table 1.

Table I. Wong's responsibility manifesto

I alone am responsible for all the major choices in life - the kind of person I want to be, the career path I want to follow, the future I want to create, and the person I want to marry.

I alone am responsible for my own wellbeing - physical, psychological, social, and spiritual. Therefore, I will do what is necessary each day to improve my wellness.

My optimism in eventual success depends on taking responsibility for my failures rather than making excuses or blaming external factors. My confidence comes from believing in the noble value of my goal, making sacrifices, doing my best each day, and praying for wisdom, guidance, and strength from God.

I am morally accountable for everything I say or do. I will never knowingly say or do anything to harm another person, but I am not responsible for how others react.

I am accountable for the quality and outcome of my work as a free agent.

I will reap whatever I sow. That is the natural law of karma.

I am responsible for my family, society, the world, and planet earth to the extent of my ability and influence.

My personal, social, and spiritual responsibility is always my main concern. That is how I can always maintain my self-respect and dignity, no matter what others say about me.

Happiness is having a clear conscience before God and having inner peace in my waking hours and in my sleep, knowing that I have done everything to the best of my knowledge and ability.

Responsibility is the only key to living a meaningful and productive good life.

Note. The table was created from "What is the greatest need today? Responsibility is the key to surviving and thriving in dangerous times", by Wong, P. T. P., 2019b. http://www.drpaulwong.com/what-is-the-greatest-need-today-responsibility-isthe-key-to-surviving-and-thriving-in-dangerous-times /

Both research and clinical evidence support his view (e.g., Wong, 2010, 2012). The corollary is also true - the lack of responsibility may lead to addiction (e.g., Rise \& Halkjelsvik, 2019; Wong et al., 2013) and crimes (TrivediBateman, 2020). Given the important role of responsibility in wellbeing and health, the main aim of the present paper is to validate the responsibility measure based on the Responsibility Checklist originally published in Wong (2019b).

\section{Conceptualization of Responsibility}

Specifically, responsibility is a broad construct characterized in different ways (e.g., moral, social, or personal responsibility; Sheldon et al., 2018) and is conceptualized as "feeling accountable for one's decisions and actions, reliable and dependable to others, and empowered to act on issues within one's control." (Wray-Lake \& Syvertsen, 2011, pp. 12). However, from the perspective of existential positive psychology (Wong, 2019a), responsibility is inextricably linked to the phenomenon of freedom and living an authentic life. From the existential perspective (Guignon, 1998; Jean-Paul Sartre 1973; Moeinikorbekandi, 2013; Wong, 2017), responsibility is predicated on individual freedom. We can transcend our genes, environment, and history only through the responsible exercise of freedom of choice.

According to Frankl (1946/1985), responsibility is conceptualized as "responsibleness" to the demands of life, and essential for living a meaningful life. Without responsibility, society will degenerate into chaos. Frankl's genius was identifying responsibility as an important half of the freedom-responsibility pair, essential for launching the quest for meaning and self-transcendence. As the first tenet of logotherapy, freedom-of-will is a necessary step for a meaningful life; it hypothesizes that people who believe in the inherent human capacity for freedom and responsibility, regardless of circumstances, will show higher autonomy, authenticity, and live more meaningful lives than those without such beliefs (Wong, 2014). Thus, apart from a deep sense of responsibility, all the activities designed to achieve meaning in life would not survive the inescapable trials and temptations in human life. 
Although responsibility is conceptualized in many different ways, researchers have commonly focused on the personal and social aspects of it (e.g., Giacalone et al., 2008; Sheldon et al., 2018; Wong, 2019b; Wray-Lake \& Syvertsen, 2011). Personal responsibility means that an individual is accountable to oneself and the needs or wellbeing of others (Ruyter, 2002), and this construct emphasizes self-accountability, representing an individual's behaviors and choices that can impact oneself and others (Mergler \& Shield, 2016). In addition to personal responsibility, social responsibility is related to values that promote moral, prosocial, and civic behaviors of individuals (Wray-Lake \& Syvertsen, 2011) and involves decisions and actions that serve to benefit others and society (Martins et al., 2015; Wong, 2019b).

Individuals with high social responsibility are more likely to help and respect others and contribute to society (Mergler, 2017; Wray-Lake \& Syvertsen, 2011). Wray-Lake and Syvertsen (2011) have proposed that social responsibility comprises of two key constructs including the social relationships and a moral sense of care and justice, and this structure refers to be a value-orientation that promotes an individual's positive behaviors (e.g., moral, prosocial), which serve to benefit others and contribute to society (Wray-Lake \& Syvertsen, 2011). Given these conceptualizations, social and personal responsibility can be characterized by separate, but related, aspects of overall responsibility (Mergler, 2017).

The literature has also suggested that responsibility is a powerful resource for healthy development and the wellbeing of individuals (Arslan \& Y1ldırım, 2021; Martins et al., 2015, 2017; Wong, 2019b; Wong \& Wong, 2012). Specifically, previous studies have focused on the importance of personal responsibility in the education field and empathized that the sense of responsibility plays a vital role in promoting positive youth development and wellbeing (Martins et al., 2015; Mergler, 2017; Wray-Lake \& Syvertsen, 2011; Zimmerman \& Kitsantas, 2005). Responsibility promotes youth's healthy functioning and skills and promotes positive behaviors; thereby, it provides a successful transition from adolescence to adulthood (Martins et al., 2017).

According to Frankl (1946/1985) and Wong (2012), responsibility equals meaning, and following Frankl, Wong defines meaning in terms of the Purpose, Understanding, Responsibility, and Enjoyment (PURE) model. According to the PURE model that has been developed with the context of the meaning-management theory (Wong, 2016; Wong \& Wong, 2012), adaptive choices and decisions do not only provide satisfying and successful outcomes for the individuals but also contribute to others' wellbeing and meet moral requirements. Specifically, responsibility is identified as a key construct of flourishing, resilience, and healthy functioning of individuals in this framework (Wong, 2010; Wong \& Wong, 2012).

Responsible action refers to the behavioral component of the model, which includes doing what is right, finding the right solutions, making mends, appropriate reactions and actions, and taking actions that are congruent with the highest values (Wong, 2010). Wong (2010) has also emphasized the importance of responsible actions to live a purposefully and meaningfully life, and he has argued that responsibility is an important resource to thriving and surviving of individuals and society in difficult times (Wong, 2019b).

In addition, given the self-determination theory (Deci \& Ryan, 2000), individuals with high self-determination feel responsible for their decisions and behaviors. Autonomous functioning helps individuals to make better decisions and choices (Ryan et al., 2012). This framework instantiates the concept of autonomy within the selfregulation approach and proposes that individuals who use self-regulated strategies are more likely to feel themselves responsible for their own choices and behaviors (Ryan et al., 2012). Self-determination may thus provide important implications for understanding of the development of responsibility constructs. As sketched above, the literature has theoretically and empirically suggested that responsibility is one of the keys to wellbeing and the good life, and the ability to make adaptive choices and decisions is paramount. Considering the important of this construct for individual and society, it is critical to develop a new effective scale for assessing of responsibility construct. Although many questionnaires are available to measure the sense of responsibility, most of them have been developed and validated for use with students (for the review, see Mergler, 2017). Moreover, these measures have commonly been used to assess personal responsibility, and the social aspect of responsibility remains underresearched. Compared to the available instruments, the development of a valid and reliable screener for both personal and social responsibility can provide efficient measurement for researchers and practitioners. The purpose of the current study is to investigate the initial development and validation of the Responsibility Questionnaire (RQ) to measure the sense of responsibility of individuals. 


\section{Method}

\section{Participants}

Participants included two independent samples, comprising of 284 adults, ranging in age between 18 and 84 years. Sample 1 was used to conducted the exploratory factor analysis and comprised of 152 adults (65\% female), ranging in age from 18 to 82 years $(M=43.18, S D=14.68)$. The participants reported their socioeconomic status (SES) reported as follow: $<10000 \$=22 \%, 10000-30000 \$=25 \%, 30000-40000 \$=15 \%$, and $40000 \$$ and upper $=18 \%$. Sample 2 was used to conduct the confirmatory factor analysis. The sample consisted of 132 adults (56\% female), ranging in age from 18 to 84 years $(M=29.08, S D=12.45)$. The participants reported their socioeconomic status (SES) reported as follow: $<10000 \$=35 \%, 10000-30000 \$=24 \%, 30000-40000 \$=7 \%, 40000 \$$ and upper $=11 \%$, and prefer not to say $=23 \%$. An online survey was created using Google Forms and presented to the participants who volunteered to participate in the study.

\section{Measures}

Responsibility Questionnaire (RQ). The scale item pool was generated by recommendations from literature on scale development (DeVellis, 2017; Tay \& Jebb, 2017; Worthington \& Whittaker, 2006). After outlining a rationale for developing a new scale for measuring responsibility, a two-step process was performed to create the pilot items of the RQ. Literature and existing measures that have used to assess the personal and social responsibility were first reviewed to produce pilot items for the measure (Mergler, 2017; Mergler \& Shield, 2016; Sheldon et al., 2018; Wong, 2019b). The scale's items were created to reflect the hypothesized responsibility dimensions "responsibility to self" and "responsibility to others and society" as they are represented in the literature. After reviewing the theoretical and empirical literature, a total of 24 pilot items were drafted, and two experts, who were tenured professors in the fields of clinical psychology, were invited to review the RQ item pool. Following the expert feedback, the item pool was then edited into a revised form, and the final draft was created containing 17 items. All items were rated on a 5-point Likert-type scale ( $1=$ strongly disagree, $2=$ disagree, $3=$ undecided, $4=$ agree, and $5=$ strongly agree). The final version of the measure is presented in Table 3.

Personal Responsibility Scale (PRS). The PRS is an 8-item self-report measure developed to assess the personal responsibility of individuals (Sheldon et al., 2018). All items of the scale are scored using a 5-point Likert scale, ranging from $1=$ strongly disagree to $5=$ strongly agree (e.g., "I can almost always be counted on to be on time and to keep my promises"). Previous research provided evidence supporting that the scale had adequate internal reliability estimates (Sheldon et al., 2018). Similarly, the internal reliability estimate of the scale with the present sample was adequate, see Table 2 .

Satisfaction with Life Scale (SWLS). Wellbeing was measured using the SWLS, which is a 5-item self-report measure developed to assess individuals' cognitive judgments of life (Diener et al., 1985). The scale's items scored based on a 7-point Likert scale, ranging from $1=$ strongly disagree to $7=$ strongly agree (e.g., "In most ways my life is close to my ideal"). Research supported that the scale had the internal and test-retest reliability estimates (Pavot \& Diener, 1993). In the present study, the internal reliability estimate of the measure was strong, see Table 2.

Patient Health Questionnaire (PHQ). Psychological distress was assessed using the PHQ-4 designed to measure the depression and anxiety of individuals (Kroenke et al., 2009). All items of the PHQ are scored using a 3-point Likert scale, ranging between $0=$ not at all and $3=$ nearly every day (e.g., "Feeling nervous, anxious, or on edge"). Past research supported that the scale was a brief and effective measure to assess psychological distress and had strong internal reliability estimates (Kroenke et al., 2009). Findings from this study showed that the internal reliability estimate of the scale was strong, see Table 2.

Conscientiousness Scale (CS). Conscientiousness was measured using the items from the Big Five Inventory (BFI) (John \& Srivastava, 1999). Conscientiousness includes nine items scoring based on a 5-point Likert scale, ranging from $1=$ disagree strongly to $5=$ agree strongly (e.g., "Is a reliable worker", "Tends to be lazy"). Research provided evidence supporting that the scale had strong internal reliability estimates (John \& Srivastava, 1999). Findings from this study also showed that the scale had strong internal reliability estimate, see Table 2. 


\section{Data Analyses}

All statistical analyses were performed with SPSS version 25 and AMOS version 24. Exploratory factor analysis (EFA) was first conduct to examine the factor structure of the measure using the principal axis factoring method with a promax rotation with the first sample of the study. Prior to examining the EFA output, the number of indices were checked including the Kaiser-Meyer-Olkin (KMO> .50), Bartlett's Test of Sphericity $(<.05)$ the matrix determinant $(>0)$, and item communalities $(<.30)$ (Field, 2009; Tabachnick \& Fidell, 2013). After checking these criteria, the EFA output were interpreted using factor loading $\geq .40$, cross-loading $\geq .32$, and theoretical interpretability (Field, 2009; Stevens, 2009; Tabachnick \& Fidell, 2013). As a second step, confirmatory factor analysis (CFA) was conducted to test the latent structure of the measure with the second sample of the study. The CFA results were interpreted using data-model fit statistics and their cut-of points: SRMR (standardized root mean square residual) and RMSEA (root mean square error of approximation) scores between .05 and .08 indicated adequate data-model fit, while values $<.05$ were accepted good data-model fit. CFI (comparative fit index) and TLI (Tucker Lewis index) scores $>.90$ were accepted as adequate and those exceeding .95 were interpreted as good data-model fit (Hooper et al., 2008; Kline, 2015; Mueller \& Hancock, 2008). Additionally, the latent construct reliability $(H)$ estimate was examined for the RQ latent structures, and the estimate $\geq .70$ indicated adequate (Mueller \& Hancock, 2008). In the final phases of the analyses, concurrent validity was conducted. Bivariate correlation was first performed to explore the relationship between the observed RQ scales and criterion variables. Findings from this analysis were interpreted using traditional standards: .10-.29 = small, .30-.49= moderate, and $\geq .50=$ large. Subsequently, a pair of latent variable path analyses (LVPA) was conducted to examine the predictive effect of the second and first-order measurement model on concurrent variables with the second sample of the study. Results of the LVPA were interpreted using the standardized regression estimate $(\beta)$ scores and squared-multiple correlations $\left(R^{2}\right)$ : .01-.059 = small, .06-.139= moderate, $\geq .14=$ large (Cohen, 1988).

\section{Results}

\section{Factor structure}

Findings from the first EFA indicated that the $17 \mathrm{RQ}$ items provided five factors with eigenvalues $>1$ that accounted for approximately $46 \%$ of the variance and were characterized by lack of singularity (Bartlett's $\chi^{2}=761.11, d f=$ $136, p<.001$ ), an adequate sample size (Kaiser-Meyer-Olkin $[\mathrm{KMO}]=.76$ ), no multicollinearity (Matrix determinant $>0$ ), and moderate-to-strong communality estimates $\left(h^{2}\right.$ range $\left.=.32-.71\right)$. Results of the pattern matrix indicated two non-loading items $(\lambda \leq .40)$ and six cross-loading items $(\lambda>.32$ across more than one factor).

Table 2. Scale Items, responsibility domains, and factor loadings

\begin{tabular}{|c|c|c|c|c|c|c|c|}
\hline \multirow{2}{*}{ Items } & \multicolumn{2}{|c|}{ EFA } & \multicolumn{5}{|c|}{ CFA } \\
\hline & PRS & SRS & $\lambda_{1}$ & $\ell_{1}^{2}$ & $\lambda_{2}$ & $\ell^{2}{ }_{2}$ & $H$ \\
\hline Personal Responsibility Scale & - & - & - & - & .89 & .79 & .80 \\
\hline $\begin{array}{l}\text { I discipline myself to make the best use of my time doing } \\
\text { meaningful things }\end{array}$ & .56 & -.03 & .55 & .31 & - & - & - \\
\hline $\begin{array}{l}\text { When I am responsible for something, I always find ways to get it } \\
\text { done even without the necessary resources and help. }\end{array}$ & .82 & -.09 & .59 & .35 & - & - & - \\
\hline I am conscientious in whatever I do, big or small & .70 & -.05 & .76 & .58 & - & - & - \\
\hline $\begin{array}{l}\text { Even in difficult circumstances, I still choose to do what is right } \\
\text { rather than what is expedient }\end{array}$ & .58 & .25 & .80 & .64 & - & - & - \\
\hline Social Responsibility Scale & - & - & - & - & .91 & .82 & .84 \\
\hline I am accountable for all my decisions and actions. & .21 & .50 & .75 & .56 & - & - & - \\
\hline $\begin{array}{l}\text { I have responsibility for my family, society, the world, and planet } \\
\text { earth to the extent of my ability and influence }\end{array}$ & .00 & .63 & .70 & .48 & - & - & - \\
\hline I am morally accountable for how I treat others & -.22 & .80 & .71 & .50 & - & - & - \\
\hline I am responsible to do my part to make the world a better place & .09 & .58 & .80 & .63 & - & - & - \\
\hline Overall Responsibility Scale & - & - & - & 一 & 一 & - & .90 \\
\hline
\end{tabular}

Note. $\mathrm{EFA}=$ exploratory factor analyses; $\mathrm{CFA}=$ confirmatory factor analysis. $\lambda 1=$ item loadings for first-order factors; $\ell 21=$ indicator reliability for first-order factor items; $\lambda 2=$ first-order factor loading for second-order factor; $\ell 22=$ indicator reliability for second-order factor indicators; $\mathrm{H}=$ latent construct reliability for first-order and second-order factors, PRS= Personal Responsibility Scale, SRS= Social Responsibility Scale. 
Moreover, findings from the parallel analysis and visual inspection of the scree plot suggested a two-factor solution would be a better fit to the data. Considering these outcomes, the two-factor structure was ultimately examined as the preferred model. Following excluding the non-loading and cross-loading items, the EFA was rerun constraining a two-factor solution. Further findings revealed the two-factor solution, comprising of 8 items accounted for $46 \%$ of the variance, with eigenvalues of 1.54 and 3.15. All factor loadings on two factors were strong exceeding .50, with no cross-loadings. Cross-loadings for all items were negligible $(\lambda$ range $=-.22-.25)$. Factor loadings of the scale were robust, with values ranging from .50 to .82 , as shown in Table 2 .

Subsequently, the high-order CFA was conducted to confirm the latent structure of the scale using the second sample of the study. Findings from the CFA provided the good data-model fit statistics to the two-factor measurement model with 8 items, which were indicators of two latent constructs (i.e., personal responsibility and social responsibility) $-\chi^{2}=34.86, d f=19, p<.05, \mathrm{CFI}=.96, \mathrm{TLI}=.94, \mathrm{SRMR}=.045, \mathrm{RMSEA}[95 \% \mathrm{CI}]=.080$ $[.035, .12]$ - that was characterized by robust latent structure reliability estimates $(H$ range $=.80-.90)$. Further results also showed that the scales had strong factor loadings, ranging from .55 to .80 , as shown in Table 2 .

Table 3. Descriptive statistics for the $R Q$ and concurrent validity variables

\begin{tabular}{lcccccc}
\hline Scales & Range & $M$ & $S D$ & Skewness & Kurtosis & $\alpha$ \\
\hline Overall responsibility & $8-40$ & 30.39 & 8.00 & -1.52 & 1.86 & .86 \\
Personal responsibility & $4-20$ & 14.55 & 3.98 & -1.32 & 1.18 & .92 \\
Social responsibility & $4-20$ & 15.84 & 4.26 & -1.49 & 1.70 & .94 \\
Life satisfaction & $5-35$ & 22.09 & 8.53 & -.50 & -.83 & .94 \\
Psychological distress & $0-12$ & 4.60 & 3.46 & .50 & -.43 & .83 \\
Personal responsibility & $8-40$ & 39.19 & 7.93 & -1.23 & 1.11 & .93 \\
Conscientiousness & $16-45$ & 32.42 & 6.15 & -.05 & -.34 & .78 \\
\hline
\end{tabular}

Lastly, descriptive statistics and the internal reliability estimate of scale was performed. Findings from descriptive statistics indicated that the final 8 -item measure and its subscales were relatively normally distributed (skewness and kurtosis $<|2|$ ), and item-total correlation estimates were large ( $r$ range $=.63$ to .84$)$. Reliability analyses also indicated that the scale and it sub-dimensions had strong internal reliability coefficients ( $\alpha$ range $=.86-$ to- .94$)$, as shown in Table 4.

Table 4. Bivariate correlations between the RQ and concurrent validity scales

\begin{tabular}{lccc}
\hline & \multicolumn{3}{c}{ Responsibility } \\
\cline { 2 - 4 } Concurrent validity scale & PRS & SRS & ORQ \\
\hline Life satisfaction & $.59^{* *}$ & $.54^{* *}$ & $.58^{* *}$ \\
Psychological distress & $-.32^{* *}$ & $-.33^{* *}$ & $-.34^{* *}$ \\
Personal responsibility & $.81^{* *}$ & $.78^{* *}$ & $.82^{* *}$ \\
Conscientiousness & $.52^{* *}$ & $.45^{* *}$ & $.50^{* *}$ \\
\hline
\end{tabular}

Note. $^{* *} p<.001 . \mathrm{PRS}=$ Personal Responsibility Scale, $\mathrm{SRS}=$ Social Responsibility Scale, ORQ= Overall Responsibility Scale.

\section{Concurrent Validity}

Bivariate correlation analysis was first performed to investigate the correlation between the RQ and criterion variables (i.e., life satisfaction, psychological distress, personal responsibility, conscientiousness) selected for concurrent validity. Findings from correlation analysis revealed that the scale was moderately associated with psychological distress $(r=-.34, p<.001)$ as well as had large correlations with life satisfaction $(r=.58, p<.001)$, personal responsibility $(r=.82, p<.001)$, and conscientiousness $(r=.50, p<.001)$, as shown in Table 4 . Subsequently, the latent variables path model, which preferred to investigate the predictive power of the first and second-order RQ measurement model on life satisfaction and psychological distress, revealed that the high-order measurement had positive and significant predictive effect on life satisfaction $(\beta=-.57, p<.001)$ and negative predictive effect on psychological distress $(\beta=-.47, p<.001)$, accounting for approximately large of variance in the variables $\left(R^{2}=.14-.36\right)$, see Figure 1 . 


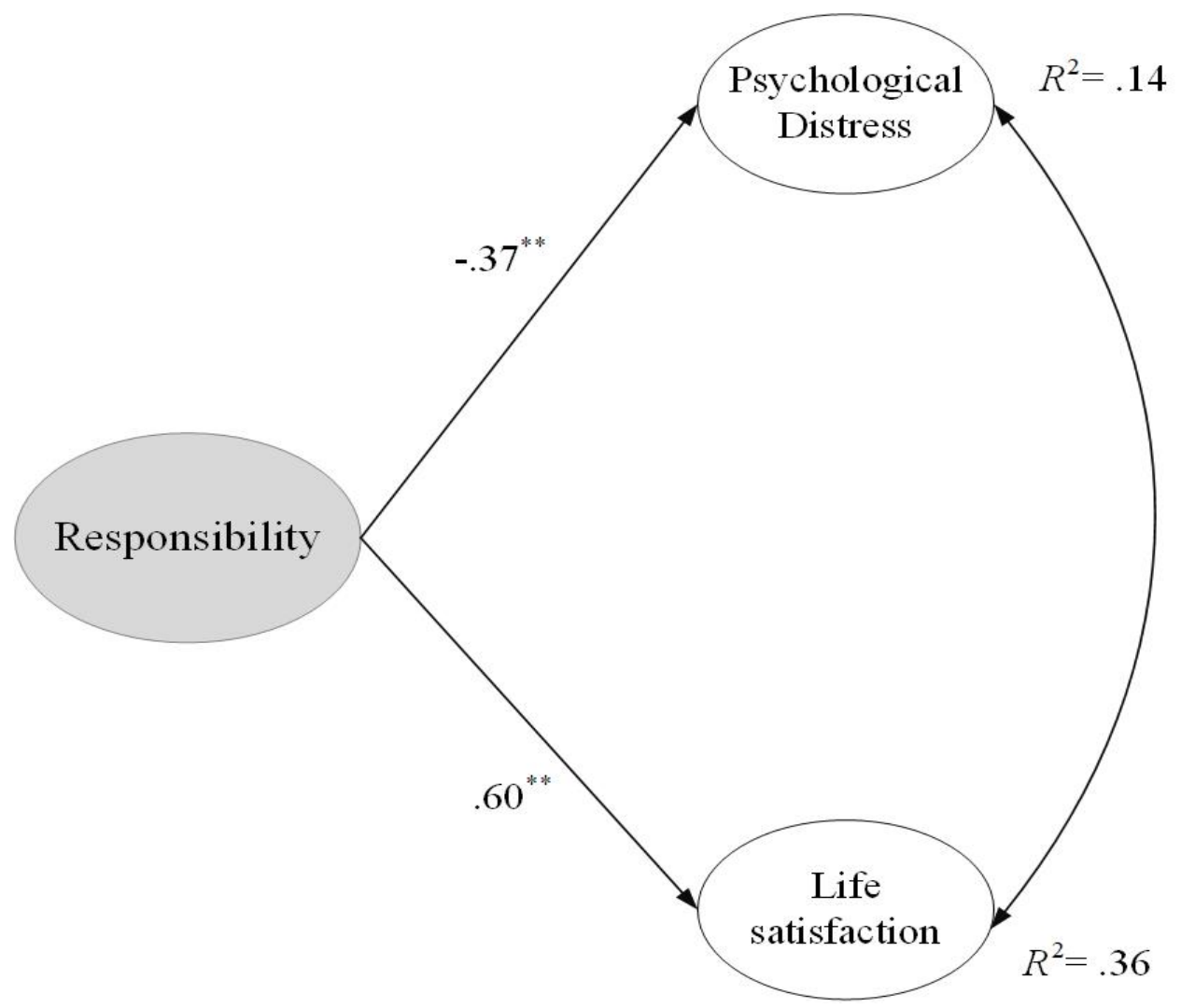

Figure I. The predictive effect of responsibility on life satisfaction and psychological distress Note. ${ }^{* *} p<.001$

\section{Discussion}

Responsibility is an important construct to mental health and wellbeing and helps individuals make better decisions and choices (Ryan et al., 2012). Responsibility provides satisfying and successful outcomes for people and contribute to others' wellbeing (Wong, 2016; Wong \& Wong, 2012). Therefore, this structure is a key to improve flourishing, resilience, and healthy functioning of individuals (Wong, 2010; Wong \& Wong, 2012). Given the literature supporting the importance of responsibility to living a meaningful and happy life, it is critical to develop a scale for assessing of responsibility construct. The purpose of the present study is to investigate the initial development and validation of the Responsibility Questionnaire (RQ) to assess the sense of responsibility of individuals. Findings from exploratory factor analysis revealed the RQ provided a two-factor solution comprising of 8 items that accounted for $46 \%$ of the variance, with equal items targeting characteristics of both personal and social responsibility. After examining the factor structure of the measure, confirmatory factor analysis was used to confirm the latent structure of the measure (Figure 2). Findings of this analysis supported the two-factor latent structure, providing provided good data-model fit statistics and by robust latent structure reliability estimates. Further results also showed that the internal reliability of the scale and its subscales were strong. Finally, the correlation analysis and latent path model were conducted to examine the concurrent validity of the measure. Findings from correlation analysis first indicated the moderate-to-large association between responsibility and life satisfaction, personal responsibility, and psychological distress. Subsequently, the latent path model revealed that the first-and high-order measurement model had positive and significant predictive effect on life satisfaction and negative predictive effect on psychological distress, accounting for approximately large of variance in the variables.

Responsibility plays an essential role in the lives of people, influencing the choices they make and the willingness they show to hold themselves accountable for these choices (Mergler \& Shield, 2016; Wong, 2016). Measuring this construct might help support people who may be making inappropriate decisions and choices and contribute to developing prevention and intervention services targeting to promote their mental health and wellbeing. Therefore, the present study has provided a number of methodological and empirical implications for research and practice. At this particular juncture of history, many young people are suffering from both too much freedom and too little responsibility. On the one hand, Western culture encourages young people to hold the attitude that: "I want to do whatever I want to do"; thus, anything that interfere with such egotistic pursuit would be opposed as an infringement of their personal freedom. On the other hand, the current de-emphasis of personal responsibility 
means that when young people do whatever they want, they do not realize that they are not free from the consequences of their behavior. Often, their parents have to step in to bail them out, but it is unlikely that they can create a preferred future for themselves without a sense of responsibility.

That is why Wong (2019b) emphasizes that responsibility is the key to surviving and thriving in difficult times. No one is an isolated island. Whatever we do affect others; thus, personal responsibility involves social responsibility. We are more likely to prosper as individuals only when our society is safe, healthy, and prosperous. From the existential positive psychology perspective, responsibility is a master virtue which make all other virtues possible:

1. Since I am responsible for my life, I need courage to pursue my authentic path.

2. Since life is complex, competition is strong. I am responsible to develop knowledge and wisdom.

3. Since I am just one member of the human family, I am responsible to treat others with humanity.

4. Since I am the citizen of a society, I responsible to advocate social justice for all.

5. I am responsible to regulate my own emotions and desires and seek temperance to avoid harming myself and others.

6. Since my existence depends on the support from many people and a higher power, I need to seek transcendence and serve some entity greater than myself.

In his book Fear and Trembling, Kierkegaard (1843/1983) used the Biblical story of Abraham's sacrifice of Isaac to argue that personal responsibility is taking a leap of faith to rise above one's own desires and feelings in order to fulfil one's "telos". One's life becomes meaningful when one takes the courageous action to become what one ought to be. According to Hanson (2020), "There is meaning in life for Kierkegaard precisely because there is a constitutive gap between the person I would be and the person I currently am." Meaning is found in the struggle to become one's ideal self.

Although the present study has important implications for research and practice, which were mentioned above, the results should be considered in light of some limitations. First, the sample of the study included adults, which were selected using a convenience sampling approach. Further research should be conducted to increase the ability to generalize the findings of this study. Second, data were collected using a web-based online survey, which might restrict gathering data from diverse populations (e.g., rural residents). Therefore, the psychometric properties of the scale could be examined with other populations. Furthermore, the reliability of the measure was examined using internal reliability $(\alpha)$ estimates. Additional reliability analyses (e.g., test-retest) would be useful to provide evidence for the utility of the measure. Moreover, the validity of the measure was examined utilizing latent path and correlation analysis with a few criterion variables. Therefore, future studies could present further insights into the validity of the scale utilizing additional criterion measures and methods. Finally, the cross-cultural invariance of the RQ would provide additional evidence concerning a better understanding of the social-cultural indicators of the sense of responsibility.

In sum, the existential view adds a dimension of depth of understanding responsibility and meaning in life as conceptualized by American positive psychology. The present scale commands itself as a useful tool to research the role of responsibility not only in meaningful living, but in various virtues as suggested above.

\section{Compliance with Ethical Standards}

\section{Ethical Standards}

All study procedures involving human participants followed institutional and/or national research committee ethical standards and the 1964 Helsinki declaration and its later amendments or comparable ethical standards. Informed consent was obtained from all participants included in the study.

\section{Declaration of Conflicting Interests}

The author(s) declared no potential conflicts of interest with respect to the research, authorship, and/or publication of this article.

\section{Funding}

The author(s) received no financial support for the research, authorship, and/or publication of this article. 


\section{Data Availability}

The datasets generated during and/or analyzed during the current study are available from the corresponding author on reasonable request.

\section{ORCID}

Gökmen Arslan (D) https://orcid.org/0000-0001-9427-1554 Paul T. P. Wong Dhttps://orcid.org/0000-0003-4982-8127

Received: Aguste 22, 2021

Accepted: September 27, 2021

Published Online: September 29, 2021

\section{References}

Arslan, G. \& Y1ldırım, M. (2021). Perceived risk, positive youth-parent relationships, and internalizing problems in adolescents: Initial development of the Meaningful School Questionnaire. Child Indicators Research, 14, 1911-1929. https://doi.org/10.1007/s12187-021-09841-0

Austen, I. (2021, September 3). Vaccine passports roll out, and so do unruly anti-vaccine protests. The New York Times. https://www.nytimes.com/2021/09/03/world/canada/vaccine-passports-protests.htm

Ball, P. (2020, May 13). Anti-vaccine movement could undermine effors to end coronavirus pandemic, researchers warn. Nature. https://www.nature.com/articles/d41586-020-01423-4

Chen, C., Chang, S., \& Wu, H. (2021). discovering and approaching mature happiness: The implementation of the CasMac Model in a university english class. Frontiers in Education, 6, 648311. https://doi.org/10.3389/feduc.2021.648311

Cohen, J. (1988). Statistical power analysis for the behavioralsciences (2nd ed.). Lawrence Erlbaum.

De Ruyter, D. (2002). The virtue of taking responsibility. Educational Philosophy and Theory, 34(1), 25-35. https://doi.org/10.1111/j.1469-5812.2002.tb00283.x

Deci, E. L., \& Ryan, R. M. (2000). The "What" and "Why" of Goal Pursuits: Human Needs and the SelfDetermination of Behavior. Psychological Inquiry, 11(4), 227-268. https://doi.org/10.1207/S15327965PLI1104_01

DeVellis, R. F. (2017). Scale development: Theory and applications. Sage Publications, Inc.

Diener, E., Emmons, R. A., Larsen, R. J., \& Griffin, S. (1985). The satisfaction with life scale. Journal of Personality Assessment, 49(1), 71-75.

Field, A. (2009). Discovering statistics using SPSS. Sage publications.

Frankl, V. E. (1985). Man's search for meaning. Washington Square Press (Originally published in 1946)

George, L. S., \& Park, C. L. (2016). Meaning in life as comprehension, purpose, and mattering: Toward integration and new research questions. Review of General Psychology, 20(3), 205-220. https://doi.org/10.1037/gpr0000077

Giacalone, R. A., Jurkiewicz, C. L., \& Deckop, J. R. (2008). On ethics and social responsibility: The impact of materialism, postmaterialism, and hope. Human Relations, 61(4), 483-514. https://doi.org/10.1177/0018726708091019

Guignon, C.(1998). Freedom and responsibility. In Existentialism. In T. Crane (Ed.), The Routledge Encyclopedia of Philosophy. Taylor and Francis. https://doi.org/10.4324/9780415249126-N020-1

Hanson, J. A. (2020, November 4). Meaning in life, imagination, and Søren Kierkegaard by Jeffrey A. Hanson. The Harvard Human Flourishing Program. https://hfharvard.medium.com/meaning-in-life-imagination-ands\%C3\%B8ren-kierkegaard-by-jeffrey-a-hanson-2be72f0953ee

Hooper, D., Coughlan, J., \& Mullen, M. R. (2008). Structural Equation Modelling: Guidelines for Determining Model Fit. Electronic Journal of Business Research Methods, 6(1), 53-60.

John, O. P., \& Srivastava, S. (1999). The Big-Five trait taxonomy: History, measurement, and theoretical perspectives. In L. A. Pervin \& O. P. John (Eds.), Handbook of personality: Theory and research (pp. 102138). Guilford Press.

Kierkegaard, S. (1983). Fear and trembling (Trans. H. V. Hong). Princeton University Press (Originally published in 1843) 
Kline, R. B. (2015). Principles and practice of structural equation modeling. Guilford .

Kroenke, K., Spitzer, R. L., Williams, J. B. W., \& Lowe, B. (2009). An Ultra-Brief Screening Scale for Anxiety and Depression: The PHQ-4. Psychosomatics, 50(6), 613-621. doi: 10.1176/appi.psy.50.6.613

Lopez, S. J., \& Snyder, C. R. (2009). The Oxford handbook of positive psychology. Oxford University Press.

Martela, F., \& Steger, M. F. (2016). The three meanings of meaning in life: Distinguishing coherence, purpose, and significance. The Journal of Positive Psychology, 11(5), 531-545. https://doi.org/10.1080/17439760.2015.1137623

Martins, P., Rosado, A., Ferreira, V., \& Biscaia, R. (2015). Examining the validity of the personal-social responsibility questionnaire among athletes. Motriz: Revista de Educação Física, 21(3), 321-328. https://doi.org/10.1590/S1980-65742015000300014

Martins, P., Rosado, A., Ferreira, V., \& Biscaia, R. (2017). Personal and Social Responsibility Among Athletes: the Role of Self-Determination, Achievement Goals and Engagement. Journal of Human Kinetics, 57(1), 39-50. https://doi.org/10.1515/hukin-2017-0045

Mergler, A. (2017). Personal responsibility: an integrative review of conceptual and measurement issues of the construct. Research Papers in Education, 32(2), 254-267. https://doi.org/10.1080/02671522.2016.1225801

Mergler, A., \& Shield, P. (2016). Development of the Personal Responsibility Scale for adolescents. Journal of Adolescence, 51, 50-57. https://doi.org/10.1016/j.adolescence.2016.05.011

Moeinikorbekandi, F. (2013). Kierkegaard's View on the Suffering Aspects of Life and the Role of Love in Decreasing the Suffering of Life. In A. A. Drautzburg \& J. Oldfield (Eds.), Making sense of suffering: A collective attempt. Brill. https://doi.org/10.1163/9781848881235_003

Mueller, R. O., \& Hancock, G. R. (2008). Best practices in structural equation modeling. In J. Osborne (Ed.), Best practices in quantitative methods (pp. 488-510). SAGE Publications, Inc.

Pavot, W., \& Diener, E. (1993). Review of the Satisfaction With Life Scale. Psychological Assessment, 5(2), 164 172. doi: 10.1037/1040-3590.5.2.164

Peck, M. S. (2012). The Road Less Travelled. Rider (Originally published in 1978)

Peterson, C., \& Seligman, M. E. P. (2004). Character strengths and virtues: A handbook and classification. Oxford University Press.

Peterson, J. B. (2018). 12 rules for life: An antidote to chaos. Vintage Canada.

Rise, J., \& Halkjelsvik, T. (2019). Conceptualizations of Addiction and Moral Responsibility. Frontiers in psychology, 10, 1483. https://doi.org/10.3389/fpsyg.2019.01483

Ryan, R. M., Legate, N., Niemiec, C. P., \& Deci, E. L. (2012). Beyond illusions and defense: Exploring the possibilities and limits of human autonomy and responsibility through self-determination theory. In P. R. Shaver \& M. Mikulincer (Eds.), Meaning, mortality, and choice: The social psychology of existential concerns. (pp. 215-233). https://doi.org/10.1037/13748-012

Sartre, J.-P. (1973). No exit, and three other plays. Vintage Books.

Sheldon, K. M., Gordeeva, T., Leontiev, D., Lynch, M. F., Osin, E., Rasskazova, E., \& Dementiy, L. (2018). Freedom and responsibility go together: Personality, experimental, and cultural demonstrations. Journal of Research in Personality, 73, 63-74. https://doi.org/10.1016/j.jrp.2017.11.007

Stevens, J. P. (2009). Applied multivariate statistics for the social sciences. Routledge.

Tabachnick, B. G., \& Fidell, L. S. (2013). Using multivariate statistics (6th ed.). Pearson.

Tay, L., \& Jebb, A. (2017). Scale development. In S. Rogelberg (Ed.), The SAGE encyclopedia of industrial and organizational psychology. Sage publications.

Trivedi-Bateman, N. (2020, May 15). Why young people commit crime and how moral education could help - new research. The Conversation. https://theconversation.com/why-young-people-commit-crime-and-how-moraleducation-could-help-new-research-131855

Wong, L. C. J., Thompson, G. R., \& Wong, P. T. P. (Eds.) (2013). The positive psychology of meaning and addiction recovery: Selected papers from Meaning Conferences. Purpose Research.

Wong, P. T. P. (2008). Freedom and responsibility. In K. Shelton, \& D. L. Bolz (Eds.), Responsibility 911: With great liberty comes great responsibility (p. 31-34). Executive Excellence. 
Wong, P. T. P. (2010). Meaning therapy: An integrative and positive existential psychotherapy. Journal of Contemporary Psychotherapy, 40(2), 85-93. https://doi.org/10.1007/s10879-009-9132-6

Wong, P. T. P. (2011). Positive psychology 2.0: Towards a balanced interactive model of the good life. Canadian Psychology/Psychologie canadienne, 52(2), 69-81. https://doi.org/10.1037/a0022511

Wong, P. T. P. (2012). Toward a dual-systems model of what makes life worth living. In P. T. P. Wong (Ed.), The human quest for meaning: Theories, research, and applications (2nd ed., pp. 3-22). Routledge.

Wong, P. T. P. (2014). Viktor Frankl's meaning seeking model and positive psychology. In A. Batthyany \& P. Russo-Netzer (Eds.), Meaning in existential and positive psychology (pp. 149-184). Springer.

Wong, P. T. P. (2016). Meaning centered positive group intervention. In P. Russo-Netzer, S. E. Schulenberg, \& A. Batthyany (Eds.), Clinical perspectives on meaning: Positive and existential psychotherapy. (pp. 423-445). https://doi.org/10.1007/978-3-319-41397-6_21

Wong, P. T. P. (2017). Existential theoretical framework. In A. Wenzel (Ed.), The SAGE encyclopedia of abnormal and clinical psychology (pp. 1375-1378). Sage.

Wong, P. T. P. (2019a). Second wave positive psychology's (PP 2.0) contribution to counselling psychology. Counselling Psychology Quarterly, 32(3-4), 275-284. https://doi.org/10.1080/09515070.2019.1671320

Wong, P. T. P. (2019b). What is the Greatest Need Today? Responsibility is the Key to Surviving and Thriving in Dangerous Times. Dr Paul Wong. http://www.drpaulwong.com/what-is-the-greatest-need-todayresponsibility-is-the-key-to-surviving-and-thriving-in-dangerous-times /

Wong, P. T. P. (2020). You need CasMac to get through the Covid-19 crisis stronger and happier. https://doi.org/10.31234/osf.io/psuwq

Wong, P. T. P. (2021). Existential Positive Psychology (PP 2.0) and global wellbeing: Why it is Necessary During the Age of COVID-19. International Journal of Existential Positive Psychology, 10(1), 1-16. https://www.meaning.ca/ijepp-article/vol10-no1/what-is-existential-positive-psychology-pp-2-0-why-is-itnecessary-for-mental-health-during-the-pandemic/

Wong, P. T. P., \& Wong, L. C. J. (2012). A meaning-centered approach to building youth resilience. In P. T. P. Wong (Ed.), The human quest for meaning: Theories, research, and applications (2nd ed.) (pp. 585-617). Routledge/Taylor \& Francis Group.

Wong, P. T. P., Mayer, C.-H., Arslan, G. (Eds.). (in press). COVID-19 and existential positive psychology (PP2.0): The new science of self-transcendence. Frontiers.

Wong, P. T. P., Pattakos, A., \& Arslan, G. (2020). The role of responsibility in wellbeing \& public policy in the age of COVID-19 [Abstract]. http://www.drpaulwong.com/the-role-of-responsibility-in-wellbeing-public-policyin-the-age-of-covid-19

Worthington, R. L., \& Whittaker, T. A. (2006). Scale development research. The Counseling Psychologist, 34(6), 806-838. https://doi.org/10.1177/0011000006288127

Wray-Lake, L., \& Syvertsen, A. K. (2011). The developmental roots of social responsibility in childhood and adolescence. New Directions for Child and Adolescent Development, 2011(134), 11-25. https://doi.org/10.1002/cd.308

Zimmerman, B. J., \& Kitsantas, A. (2005). Homework practices and academic achievement: The mediating role of self-efficacy and perceived responsibility beliefs. Contemporary Educational Psychology, 30(4), 397-417. https://doi.org/10.1016/j.cedpsych.2005.05.003 